\title{
VOZES FEMININAS: UM OLHAR SOBRE A PARTICIPAÇÃO DE MULHERES NO JORNALISMO BRASILEIRO
}

\author{
Ana Paula Saab de Brito* \\ Renata Elias Juliotti**
}

RESUMO

O presente trabalho busca fazer uma reflexão a partir da comparação entre duas diferentes formas de se entender o conceito de participação das mulheres na produção jornalística no País. Para isso, faz-se necessário levantar os diferentes tipos de uso do conceito de gênero por pesquisadores de Comunicação, bem como a utilização de termos como jornalismo feminino e feminismo na mídia. Nesse sentido, a proposta desse trabalho é entrecruzar os dois usos do termo.

Palavras-chave: Jornalismo feminino; Feminismo; Imprensa.

\section{ABSTRACT}

This article aims to analyze the feminine representation in the communication field in Brazil. Since this paper compares two different ways of understanding the concept of women participation in the journalistic production in the country, as it was necessary to deliberate about the different types of usage of gender concept by communication researchers, as well as the use of terms such as women journalism and feminism in the media. Therefore, the purpose of this paper is to intersect both uses of the term.

Keywords: Women Journalism; Feminism; Press.

\section{INTRODUCÃO}

Por muito tempo a imprensa brasileira noticia fatos ligados a movimentos sociais, refletindo e refratando um processo contínuo de mudanças graduais de determinados grupos sociais. Diferentes condições materiais e sociais fundamentam perspectivas distintas. No caso das mulheres, estão

Acadêmica em Comunicação Social com Habilitação em Jornalismo.

** Professora Mestre do curso de Comunicação Social do Unitoledo. anapaulasaab@hotmail.com 
relacionados diferentes significados que têm em suas vidas o trabalho remunerado, a família, os afazeres domésticos e maternais.

Em dado momento da História a mulher brasileira inicia uma trajetória de imposição social, desconstruindo perspectivas vinculadas ao estilo de vida idealizado pela sociedade desigual, e ganhando voz nos poucos espaços em que conseguia se inserir. Por muito tempo as representações sobre o gênero feminino permaneceram calcadas numa ideologia tradicional, revestida por uma tônica moderna condizente aos anseios de sua época.

O jornalismo feminino, do modo como se manifesta desde a década de 1950, representa uma das formas de segmentação de público no jornalismo no Brasil. Direcionado, inicialmente, exclusivamente ao público feminino, este tipo de produto comunicacional tem o propósito de tratar questões consideradas tipicamente femininas como moda, beleza, educação dos filhos, sexo e carreira profissional. É um segmento que marca uma época e delimita o espaço temporal a partir das temáticas que aborda, por ser um reflexo das transformações pelas quais passa a sociedade. Está estreitamente ligado ao contexto histórico que cria razões para seu surgimento, além de interferir em cada passo de sua evolução (BUITONI, 1990).

Muito tem sido escrito sobre a imprensa e as publicações feministas e suas contribuições para a divulgação e organização do movimento feminista no Brasil. Nesse contexto, intercruzamos os conceitos de jornalismo feminino e o movimento feminista que tanto influenciou as publicações dos veículos de comunicação de massa a partir da década de 50 no Brasil.

Estabelecer o título de "imprensa feminina" não é uma questão um tanto conflituosa. Este implica a existência de um oposto, uma "imprensa masculina", dificilmente delimitada. "A imprensa feminina é um conceito definitivamente sexuado: o sexo de seu público faz parte de sua natureza" (BUITONI, 1990, p. 7), ainda que a mulher seja parte fundamental da concretização dessa imprensa, tanto como leitora quanto como produtora. Tratando do jornalismo feminino em uma perspectiva histórica surge a importância de entender a representatividade do gênero na produção jornalística, bem com, suas particularidades que o tornam produto de análise e discurso.

\section{UM OLHAR NA HISTÓRIA}

Um fator positivo para os estudos da história da imprensa nos últimos tempos é a consciência da necessidade de trocar informações e discutir sobre o campo de pesquisa. O surgimento de meios de comunicação e os 
princípios por eles definidos estão relacionados ao contexto histórico do país e ao movimento feminista nacional, destacando-se o seu compromisso com uma linguagem particular e com a difusão de reivindicações e propostas diretamente relacionadas com a condição das mulheres.

Progressivamente, no decorrer da História, a mulher brasileira vem sofrendo com a desigualdade de gêneros existente nas instituições econômicas, sociais e políticas. Nesse sentido, relaciona-se o reconhecimento de que no aprendizado de ser mulher em nossa sociedade, frequentemente, a mulher é incentivada a aceitar e interiorizar uma imagem depreciativa e constrangedora de si mesma.

Historiadoras, como Michelle Perrot (1988), contribuíram para a explicitação da situação de exclusão das mulheres das narrativas históricas legitimadas. Como Perrot, outras pesquisas históricas recentes revelam a participação de mulheres em momentos muito significativos da História, como o surgimento de materiais jornalísticos feministas durante a Ditadura Militar.

Causas e lutas são travadas por mulheres militantes, sobretudo no período que vai dos anos 1850 até a conquista do voto feminino, em 1932. O primeiro momento convencionou-se chamar de primeira onda feminista e abarca as movimentações do final do século XIX e início do século XX, em que mulheres lutavam por direitos civis, especialmente o direito ao voto. No Brasil a conquista foi efetivada pelo então presidente, Getúlio Vargas, atendendo às manifestações populares da época.

O segundo momento é chamado de segunda onda e emergiu em paralelo a uma série de eventos que mudaram as feições do mundo. $\mathrm{O}$ feminismo que emergiu entre os anos 1960 e 1970 tinha fortes influências da produção de feministas como a francesa Simone de Beauvoir, autora do livro "Segundo Sexo", publicado em 1949, e da estadunidense Betty Friedan, autora de "A Mística Feminina”, publicado em 1963. Nesse novo êxtase feminista debatia-se aborto, maternidade, trabalho doméstico, sexualidade e contracepção.

Algumas das primeiras publicações, como as revistas As Variedades on Ensaios Literários (1812), a primeira revista brasileira; Museu Universal (1837); Semana Ilustrada (1860) e Revista da Semana (1901), segundo Mira (2003), tinham a pretensão de ser um grande painel de toda a civilização humana, tornando possível ao leitor se transportar para qualquer lugar com o simples virar da página. Embora não fosse seu objetivo, revistas como estas não raro traziam pequenas seções que versavam sobre família e lar para, assim, contemplar as mulheres. 
A partir de meados do século XIX, surgem vários veículos, período demarcado também pelo início da participação da mulher. O movimento feminista, inserido na produção jornalística da época, seria uma extensão, uma das esferas por onde se propagou o feminismo, e traz consigo propostas de desconstrução social no que remete à igualdade de gêneros.

A precariedade das condições de vida da mulher do século XIX impossibilitou que a imprensa feminina tomasse realmente forma. Surgiu uma ou outra publicação, produzida quase sempre por homens, de vida curta e alcance pouco expressivo. Mas não tardou para que o público feminino ganhasse espaço na imprensa e acabasse por tornar a revista um meio deste gênero por excelência. O século seguinte foi marcado por um aprimoramento das técnicas de impressão, redação e de recursos gráficos. A fotografia passou a ser cada vez mais utilizada e a imprensa deixou de ser artesanal para assumir características de empresa industrial e comercial (BUITONI, 2009, p.51).

É nesse período também que o público consumidor de meios impressos começa a se definir e se consolidar junto aos veículos: "a população aumenta, a cidade se espalha, surgem os jornais de bairro. Já havia público para revistas mundanas, ricas e luxuosas" (BUITONI, 2009, p.51). Neste contexto é que surge, então, a Revista Feminina (1914), que durou 21 anos, chegou à tiragem de 30 mil exemplares mensais e foi comercializada em todo o Brasil (BUITONI, 2009, p.56).

É a partir de fins da década de 1930, já durante os investimentos da Era Vargas, que se começa a perceber um crescimento vertiginoso no consumo de produtos jornalísticos, principalmente impressos, pois, apesar dos mecanismos de controle exercidos pelo governo, "as políticas de industrialização e de melhorias nas condições sociais das classes trabalhadoras e das camadas médias auxiliam a reforçar a imprensa, ao permitir uma ampliação do mercado consumidor" (ROMANCINI; LAGO, 2007, p.87).

Em 1959, surge Manequim, a primeira revista brasileira exclusivamente de moda; em 1961, surge Claudia, "a revista que queria ser mulher" (MIRA, 2003, p.43); e, em 1973, o país conheceu a ousadia da publicação internacional Cosmopolitan e no Brasil a revista Nova. Com um público leitor fiel, a solidificação da imprensa feminina começou a tomar forma.

Assim como outras de sua época, a revista Cláudia, do Grupo Abril, marcou uma nova transformação da produção jornalística voltada para o público feminino. O Brasil vivia em épocas de crescente expansão do capitalismo, submetendo todas as atividades, inclusive a imprensa, à lógica da 
modernização do país. As mulheres, vistas como as principais consumidoras dos novos produtos industrializados numa sociedade em processo de modernização, tornaram-se o alvo na atenção dos publicitários. A jornalista Ana Rita Fonteles Duarte ${ }^{1}$ nos mostra em sua dissertação de mestrado como, nesse sentido, Claudia inaugurou um novo estilo dentre as revistas femininas da época, investindo alto nas reportagens sobre moda e o mundo doméstico. Influenciada pelo american way of life, a "revista amiga" brasileira reafirmava os papéis tradicionais destinados às mulheres, contudo, quando as mudanças refletidas pela maior participação da mulher no mercado de trabalho e na educação já não podiam ser mais ignoradas, Claudia percebeu que precisaria dar conta das novas discussões de maneira diferente do que até então era feito por outras revistas (DUARTE, 2005).

Durante os anos de governo militar, surgiu no Brasil um tipo de imprensa denominada democrática ou alternativa. Esses jornais, com formato tabloide e muitas vezes de tiragem irregular e circulação restrita, eram vendidos em bancas, porém a venda mais significativa ocorria no âmbito da militância. Tratava-se de uma imprensa com características de esquerda e de oposição ao regime, artesanal e comercializada, prioritariamente, mão à mão, ou seja, através da venda por militantes dos movimentos populares em eventos ou nas sedes das próprias organizações.

Nesta fase de maior efervescência política e de abrandamento da censura, cresce a imprensa alternativa e aparecem também dois jornais feministas em São Paulo: O Brasil Mulher e o Nós Mulheres². De acordo com Maria Paula Araújo, esses jornais feministas foram inovadores não apenas em termos de linguagem, de reivindicações e de propostas, mas também na forma de divulgar uma visão de mundo e uma nova concepção de política (ARAÚJO, 2000, p. 159).

No período pós-moderno 1975, o primeiro jornal dirigido às mulheres e feito por mulheres foi o Brasil Mulher, publicado pela Sociedade Brasil Mulher (foram 16 edições regulares e mais quatro denominadas “extras”), de 1975 a 1980. O segundo, Nós Mulheres, publicado pela Associação de Mulheres,

\footnotetext{
Carmen da Silva: o feminismo na imprensa brasileira é produto da dissertação de mestrado defendida em 2002 por Ana Rita Fonteles Duarte no Programa de Pós-Graduação em História na Universidade Federal do Ceará. Formada em jornalismo e mestre em História, Ana Rita atualmente é doutoranda em História na Universidade Federal de Santa Catarina.

2 Em 1981, os dois jornais já não eram editados, mas a Associação das Mulheres (responsável pelas edições do Nós Mulheres) e a Sociedade Brasil Mulher continuam ativas no movimento e publicam, conjuntamente com o Centro da Mulher Brasileira, o texto "Controle da natalidade e planejamento familiar".
} 
teve oito edições, que circularam de 1976 a 1978. O fato de estarem vinculados a uma associação já mostra que esses jornais eram instrumentos de divulgação de coletivos de mulheres organizadas e, como tal, davam cobertura a assuntos não veiculados pela imprensa oficial, na época sob forte censura política, refletindo o pensamento político da militância feminista.

Em pesquisa com foco na imprensa feminista, Elizabeth Cardoso (2004) identificou o número de 53 jornais feministas circulando entre os anos 1974 e 1989. Segundo Amelinha Teles e Rosalina Santa Cruz Leite (2013, p. 82), não há dúvidas de que os primeiros jornais, bem como os primeiros grupos feministas que se organizaram no período, tinham como preocupação principal as demandas de mulheres trabalhadoras, da periferia, mães. Vale ressaltar que a imprensa feminista era quase uma modalidade alternativa dentro da própria imprensa alternativa, sendo muitas vezes considerado "jornalismo menor", alvo de pouca valorização.

A revista Grande Hotel (1947) é uma boa expoente da imprensa feminina popular do período. Ao ser a primeira a publicar histórias de amor em quadrinhos desenhados - algo que pode ser considerado o precursor do famoso gênero fotonovelas, esta publicação foi responsável por inaugurar a "literatura sentimental popular” no Brasil (BUITONI, 2009, p.90). A consagração da fotonovela viria na década seguinte, com o lançamento de Capricho (1953), da Editora Abril.

Quando a Capricho surgiu, as fotonovelas já não eram novidade. Mesmo assim, a revista conseguiu inovar ao publicar histórias completas em uma única edição, enquanto as outras revistas traziam as fotonovelas por capítulos, em várias edições. Isto garantiu seu estrondoso sucesso junto às leitoras.

Os anos 1970 trazem novos questionamentos, novas lutas. O movimento hippie, com sua filosofia de paz e amor, a pílula anticoncepcional e o movimento feminista, já consegue causar significativos abalos nas estruturas sociais da época.

Apesar das grandes transformações e movimentos culturais no Brasil, o país não deixou de ser afetado por todas as mudanças que vinham acontecendo pelo mundo. A polêmica revista Nova Cosmopolitan, por exemplo, chega em 1973 debatendo a sexualidade feminina e "colocando o prazer sexual como um direito inalienável da mulher” (MIRA, 2003, p.124). O sexo - ainda um enorme tabu - surge como um assunto dos mais importantes para a imprensa feminina e acaba por se tornar "o principal produto editorial vendido nesta década” (BUITONI, 2009, p.115): 
Nas revistas femininas, o sexo foi conquistando lugar, palmo a palmo. De referências à insatisfação da mulher casada, foi passando a matérias sobre virgindade, masturbação, orgasmo etc. e, no final da década, várias revistas femininas já conseguiam publicar, com todas as letras, os nomes dos órgãos sexuais femininos, coisa inimaginável nas contidas revistas da década de 1960 (BUITONI, 2009, p.115).

Já a pós-modernidade reflete novas atitudes e imposições do jornalismo feminino no país. Algo da maior importância acontece com as mulheres no momento pós-moderno, quando surge "a ideia de que todos os grupos têm o direito de falar por si mesmos, com sua própria voz, e de ter aceita essa voz como autêntica e legítima" (HARVEY, 2003, p.52).

É no período pós-moderno que grupos sociais historicamente excluídos ganham especial atenção, entre eles, os homossexuais, os negros e as mulheres. Estas últimas emergiram como questão, talvez nunca, antes na história.

Os anos 1990 chegam com um novo conceito de liberdade. Com o fim da ditadura já não existem assuntos que não podem ser abordados pela impressa, e a mulher desfruta plenamente das conquistas consequentes dos anos de luta dos movimentos feministas. Com o sexo já consolidado como um dos assuntos das revistas para mulheres, é neste período que temas ligados à AIDS e à camisinha passam a ser bastante abordados por este tipo de imprensa, especialmente por conta da "certa liberdade" de que as mulheres já dispunham.

A entrada do século XXI marcou o apogeu tecnológico que influenciou significantemente a produção jornalística. A primeira década do novo século foi de expansão e consolidação dessa nova forma de comunicação, com um número crescente de pessoas conectadas. Os portais de notícia passaram a concorrer com os jornais impressos, que precisaram se readaptar a essa nova realidade. O caráter capitalista dos meios de comunicação foi intensificado, acompanhando a condição financeira feminina - cada vez mais expressiva no que concerne ao poder aquisitivo.

\section{JORNALISMO FEMININO X IMPRENSA FEMINISTA}

Os estudos históricos não privilegiam o olhar sobre as mulheres. A utopia em torno da "invisibilidade" do gênero feminino é um comportamento que ajudava a construir a história das mulheres como seres que não tinham identidade própria, reforçando a visão da mulher complemento do homem (Eva costela de Adão). 
Reflexo da própria condição da mulher, cujo gênero é moldado por outras referências fundamentais de sua identidade (etnia, classe social e etc.), o movimento de mulheres no Brasil teve, sobretudo, um caráter inter-classe (Schmink, 1981). Afinal, é traço característico desta sociedade a desigualdade marcante na distribuição de seus recursos.

$\mathrm{O}$ acesso de novos espaços às mulheres, só recentemente autônomas, assinala uma aceitação de algumas culturas de direitos mais amplos. Essa visão externa de conquistas da cidadania feminina não resulta automaticamente na compreensão do que é cidadania para mulheres pensada a partir do gênero.

O feminismo é uma filosofia que reconhece que homens e mulheres têm experiências diferentes e reivindica que pessoas diferentes sejam tratadas não como iguais, mas como equivalentes (Fraisse, 1995; Jones, 1994; Louro, 1999; Scott, 1986). O movimento feminista, portanto, expõe que a experiência masculina, principalmente no mercado de trabalho, tem sido privilegiada ao longo da história, enquanto a feminina, negligenciada e desvalorizada.

Para a professora Ana Carolina Rocha Temer ${ }^{3}$, é importante destacar que as classificações dos gêneros na comunicação de massa envolvem aspectos históricos específicos e devem ser compreendidos como fenômenos datados, passando por ciclos de popularidade, baixo reconhecimento e esquecimento. Além disso, a classificação por gêneros nos meios de comunicação exige uma reflexão diferenciada em relação a esses meios e suas características gerais. Enquanto no jornal impresso, no qual a finalidade expressa do veículo é a divulgação de notícia, a classificação do material por categorias (publicidade e jornalismo) é historicamente trabalhada e aceita pelos pesquisadores, na televisão, com seu conteúdo predominantemente voltado para o entretenimento, a classificação por gêneros é diferenciada, e os produtos jornalísticos se tornam gêneros específicos dentro do conjunto da programação (TEMER, 2009).

Ao longo do século XIX, o Brasil viu tanto o jornalismo feminino quanto o feminista surgirem e se disseminarem, Um, focado na vida, no cotidiano das mulheres, caracterizava-se pelo não factual e abordava temas como literatura e moda. Aos poucos, as temáticas como beleza, sexo, educação dos filhos e carreira profissional foram se consolidando como assuntos em torno dos quais a imprensa feminina se detinha à época.

É importante destacar que, por muitas vezes, a imprensa feminina é frequentemente reduzida a um "jornalismo de trivialidades" e os estudos sobre

Professora da Faculdade de Comunicação e Biblioteconomia (FACOMB), da Universidade Federal de Goiás, doutora e mestre em Comunicação Social pela Universidade Metodista de São Paulo. 
a mulher na comunicação foram por muito tempo rejeitados, evidenciando uma defasagem de origem sexista.

$\mathrm{Na}$ mensagem, transita-se entre a linguagem culta e a informal, a científica e a literária, a séria e a maternal. Buitoni defende que "a imprensa feminina é continente para tudo que se relacione com a mulheres/ou família" (BUITONI, 1990, p. 11). Como definição, a imprensa feminina pode ser considerada como o processo e produto que abrange o jornalismo feminino e outras manifestações simbólicas, assim como nas outras formas de imprensa. Não temos neste produto um jornalismo especializado, mas um conjunto de produtos que tem segmentação própria de mercado, sendo o fator de classificação o gênero de consumidor.

Já a imprensa feminista, como subjulgado enquanto produto é marcada pela presença e o significado da relação de mulheres que se auto-organizam nas periferias, nos centros urbanos e organizações específicas em busca de garantia de direitos sociais. Mulheres ativistas preocupadas com a emancipação feminina, a discriminação, a sexualidade, o poder, reinventando uma nova forma de fazer política junto a luta reivindicativa das classes populares. Só assim pode-se entender o papel desempenhado por veículos de comunicação especializados. Abordagens distintas para uma mesma causa e um mesmo gênero de público.

\section{PARTICIPAC ÃO E UMA NOVA PERSPECTIVA}

Podemos pensar o feminismo como uma ideologia básica para a construção da identidade das mulheres como protagonistas de suas próprias histórias. Pensamos nas contribuições históricas de Simone de Beauvoir em O Segundo Sexo ${ }^{4}$, pioneira de muitas e internacionais leituras. No Brasil, lembramos Carmen da Silva, feminista que soube trabalhar em uma revista da grande imprensa, Cláudia (1963-1985) temas cruciais para o cotidiano das mulheres.

Se perante a Constituição a mulher conquistava igualdade, na vida cotidiana aqueles procedimentos limitadores dos direitos femininos continuavam vigorando. $\mathrm{O}$ acesso às profissões, discriminações, preconceitos e violências contra mulheres praticadas pelos homens de todas as posições sociais e profissionais surgiram como notícias e como temas de pesquisas. E estimularam a organização de mulheres em grupos de apoio mútuo em movimentos sociais

\footnotetext{
O Segundo Sexo é um livro escrito pela escritora, filósofa existencialista, ativista política, feminista e teórica social francesa, Simone de Beauvoir, publicado originalmente em 1949 e uma das obras mais celebradas e importantes para o movimento feminista. O pensamento de Beauvoir analisa a situação da mulher na sociedade.
} 
e em organizações não governamentais. Nesse sentido, o ativismo ganha uma nova perspectiva no jornalismo no Brasil.

Temos ainda várias publicações feministas com textos acadêmicos, destacando Estudos Feministas, no qual são apresentados textos teóricos e estudos de casos sobre a vida das mulheres. E no jornalismo brasileiro temos a participação das mulheres como profissionais jornalistas cuja capacidade de trabalho é hoje reconhecida.

Com a criação da internet, as pessoas podem se conectar de forma mais prática e ágil, temos agora uma estrutura integrada de funcionalidades e conteúdo. Diante dessa nova gama de possibilidades, movimentos sociais visualizam nas redes sociais uma possibilidade de disseminar ideias e opiniões, além de compartilhar conteúdo a respeito de determinados assuntos. $\mathrm{O}$ feminismo na web veio para esclarecer direitos primários às mulheres e revigorar a forma de se fazer jornalismo digital voltado para o gênero. É a Era do Cyberativismo que torna o jornalismo com caráter ainda mais social e significante para a sociedade.

Os gêneros não são estáticos. Eles evoluem em função da tecnologia e, principalmente, de uma relação do mercado com uma busca constante por alternativas de conquista de audiência (WOLF, 1986). A dinâmica dos gêneros nos mass media é também um mecanismo de intertextualidade que atravessa o sistema, uma característica que se acentua com a perda da especificidade midiológica (o rádio se parece com a TV e o jornal com a revista), o que faz com que cada meio de comunicação possa experimentar, receber e manifestar formas expressivas típicas de outros meios (Ibidem).

A transformação dos gêneros na mídia acontece com mudanças no conteúdo e adaptações que respondem as necessidades da recepção cotidiana, as necessidades do mercado e as próprias características do meio. Todorov (1980) entende que um gênero novo sempre é a transformação de um ou vários gêneros velhos, e que cada novo trabalho tem o potencial para influenciar mudanças ou mesmo o aparecimento de subgêneros novos, que podem mais tarde se consolidarem como gêneros diferenciados.

Dessa forma, o jornalismo feminino não trabalha a partir das informações novas ou do que tradicionalmente conceituamos como notícia. Ainda que possa haver um singelo vínculo com o imediatismo, trata-se de uma proximidade mais espontânea, sem a urgência do furo ou do ineditismo do jornalismo diário. Para este tipo de produção jornalística é mais importante expor fatos e ações que a curto, médio ou mesmo longo prazo, poderão 
contribuir para melhores condições de vida do receptor. Informações que o tornem mais saudável, mais disposto para o trabalho, mas apto a administrar o próprio tempo ou dinheiro, e todo um conjunto de questões direta ou indiretamente relativas a aspectos financeiros, mas também vinculadas ao exercício da cidadania e da apropriação dos meios de distinção simbólica.

\section{CONSIDERACÕES FINAIS}

A imprensa é sempre um excelente objeto de estudo ao conservar importantes aspectos de uma época e revelando os costumes e as inquietações que mobilizavam as pessoas em períodos distintos. A imprensa feminina, sobretudo, se mostra bastante efetiva em conceder essas pistas para que seja possível entender, hoje, o comportamento feminino ao longo do tempo, atuando, em um sentindo mais amplo, como meio de documentação da trajetória deste gênero na humanidade.

No estudo da história do jornalismo podemos descobrir como repórteres ajudam a construir novos olhares sobre o que acontece. Pensamos em como reportagens podem ser meios para uma compreensão de nossa sociedade e das situações que se repetem e podem ser corrigidas na proposição de novas perspectivas. Nesse momento, a prática de estratégicas discursivas diferenciadas e a análise do jornalismo feminino enquanto gênero ganha um novo fôlego.

Notamos que o feminismo se difunde nos meios de comunicação pela ação de profissionais e ativistas que divulgam livros, noticiam movimentos, comentam temas polêmicos e repercutem textos de cunho social e feminista.

Como analisado anteriormente, rotular como jornalismo feminino a produção voltada exclusivamente para mulheres seria presumir que existem outros produtos exclusivos para cada gênero. No entanto, o que diferencia este material de outros é a própria linguagem e simbologia social que representa.

Jornalistas, intelectuais feministas, podem com seu trabalho contribuir para organizar novos olhares, mas não podem decidir como serão as leituras dos seus textos. O jornalismo humanizado que se observa ser uma característica intrínseca da produção feminina nos meios de comunicação, com um olhar distinto sobre os fatos, é uma ressalva importante.

Como a autora Agnes Heller nos lembra, os preconceitos não dependem necessariamente da informação disponível, do conhecimento sobre um tema, eles são pré- conceitos (in: O cotidiano e a história); por isso os preconceitos determinam nossos olhares sobre o que acontece no mundo e mudá-los é um projeto para mudar a sociedade. 
O jornalismo feminino se distância e se destaca de outras possibilidades construtivas do texto, como o jornalismo informativo, literário ou mesmo cultural, cujo conteúdo soma aspectos informativos e emocionais. Por fim, ressalta-se a proposta de novos estudos que tracem uma nova possibilidade de classificação dos gêneros jornalísticos, ou uma classificação a partir de um ponto de partida diferenciado, mas que igualmente possa contribuir para aprofundar os estudos sobre o jornalismo e suas estratégias para a eficiência dos processos comunicativos.

\section{REFERENNCIAS}

ARAÚJO, Maria Paula Nascimento. A utopia fragmentada: as novas esquerdas no Brasil e no mundo na década de 70. Rio de Janeiro: FGV Editora, 2000.

BUITONI, Dulcília Schroeder. Imprensa feminina. São Paulo: Ática, 1986.

COMUNICAÇÃO \& SOCIEDADE. Ed. 182. Gêneros e gêneros: apontamentos teóricos sobre os conceitos e sua atribuição ao jornalismo feminino. Ano 30, n. 51, p. 177-200, jan./jun. 2009.

FRAISSE, G. (1995). Entre igualdade e liberdade. Estudos Feministas, 3, 164-171.

HARVEY, David. Condição pós-moderna: uma pesquisa sobre as origens da mudança. São Paulo: Loyola, 2003.

HELlER. Agnes. O cotidiano e a história. 3 ed., Rio de Janeiro, Paz e Terra, 1989.

JONES, E. (1994). Feminismo e terapia de família: os casamentos complicados podem dar certo? Em R. J. Perelberg\& A C. Miller (Orgs.), Os sexos e o poder nas famílias (pp. 75-93). Rio de Janeiro: Imago.

LOURO, G. L. (1999, 3. ed.). Gênero, sexualidade e educação: uma perspectiva pós- estruturalista. Petrópolis: Vozes.

MIRA, Maria Celeste. O leitor e a banca de revista: a fragmentação da cultura no século XX. São Paulo: Olho D'água, 2003.

ROMANCINI, Richard; LAGO, Cláudia. História do jornalismo no Brasil. Florianópolis: Insular, 2007. SCOTT, J. W. (1986). Gender: A useful category of historical analysis. The American Historical Review, 91(5), 1053-1101.

TODOROV, T. A origem dos gêneros. In: TODOROV, T. Os gêneros do discurso. São Paulo: Martins Fontes, 1980. 